NASA Technical Memorandum 105753

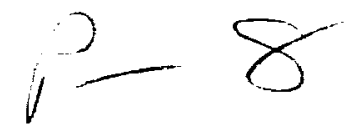

\title{
High Temperature Dielectric Properties of Apical, Kapton, Peek, Teflon AF, and Upilex Polymers
}

\author{
A.N. Hammoud \\ Sverdrup Technology, Inc. \\ Lewis Research Center Group \\ Brook Park, Ohio \\ E.D. Baumann, E. Overton, and I.T. Myers \\ National Aeronautics and Space Administration \\ Lewis Research Center \\ Cleveland, Ohio \\ and
}

J.L. Suthar, W. Khachen, and J.R. Laghari

State University of New York at Buffalo

Buffalo, New York

Prepared for the

1992 Conference on Electrical Insulation and Dielectric Phenomena sponsored by the Institute of Electrical and Electronics Engineers Victoria, British Columbia, Canada, October 18-21, 1992

\section{N/Sก}

$$
\begin{aligned}
& \text { (VASA-TM-1J5753) HIGH THMERATURT }
\end{aligned}
$$

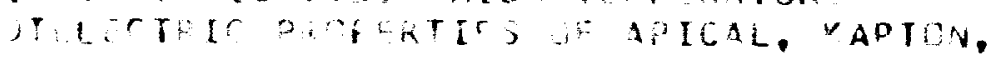

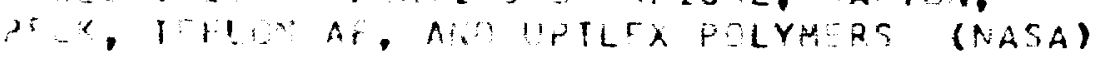

$$
\begin{aligned}
& \text { N22-2367: }
\end{aligned}
$$





\title{
HIGH TEMPERATURE DIELECTRIC PROPERTIES OF APICAL, KAPTON, PEEK, TEFLON AF, AND UPILEX POLYMERS
}

\author{
A. N. Hammoud \\ Sverdrup Technology, Inc. \\ NASA Lewis Research Center \\ Cleveland, $\mathrm{OH} \mathbf{4 4 1 3 5}$
}

\author{
E. D. Baumann, E. Overton \\ and I. T. Myers \\ NASA Lewis Research Center \\ Cleveland, OH $\mathbf{4 4 1 3 5}$
}

\author{
J. L. Suthar, W. Khachen \\ and J. R. Laghari \\ State University of New York at Buffalo \\ Buffalo, NY 14260
}

\begin{abstract}
Reliable lightweight systems capable of providing electrical power at the megawatt level are a requirement for future manned space exploration missions. This can be achieved by the development of high temperature insulating materials which are not only capable of surviving the hostile space environment but can contribute to reducing the mass and weight of the heat rejection system. In this work, Apical, Upilex, Kapton, Teflon AF, and Peek polymers are characterized for AC and DC dielectric breakdown in air and in silicone oil at temperatures up to $250^{\circ} \mathrm{C}$. The materials are also tested in terms of their dielectric constant and dissipation factor at high temperatures with an electrical stress of $60 \mathrm{~Hz}, 200 \mathrm{~V} / \mathrm{mil}$ present. The effects of thermal aging on the properties of the films are determined after 15 hours of exposure to 200 and $250^{\circ} \mathrm{C}$, each. The results obtained are discussed and conclusions are made concerning the suitability of these dielectrics for use in capacitors and cable insulations in high temperature environments.
\end{abstract}

\section{INTRODUCTION}

Electrical components and systems are often required to operate reliably in harsh environments where stresses of different kinds and intensities are encountered. High temperature constitutes one of these stresses which exists in space-based as well as terrestrial environments. Space exploration missions (lunar base), nuclear-powered space vehicles, integrated engine electronics, satellite power conditioning, and SDI systems are examples of aerospace applications where high temperatures may be present. In addition, heat is generated by power processing devices during operation. This internally-developed thermal stress greatly influences the performance of the devices through gradual degradation which eventually leads to catastrophic failure. The generation of heat and its build-up inside the device are becoming more severe as the currently emerging demand for aerospace technology places a great emphasis on increasing the energy densities and raising the power levels of space-base power systems and components. For instance, future plans for 
many space exploration missions call for a tremendous increase in the power capability up to a magnitude of the order of megawatts [1]. These requirements will certainly result in raising the operating temperature of the device/system concerned [2]. The development of high temperature insulating and dielectric materials, and power components and devices is therefore necessary to meet the challenges of advanced space power and electronic systems technology with objectives to reduce component size and weight, increase packaging density, and improve performance and reliability.

Five candidate materials were evaluated for use as high temperature capacitor dielectrics and wiring insulation. The material investigated were Upilex, Peek, Apical, Teflon AF, and Kapton polymers. Upilex is an ultra-high heat resistant polyimide film with superior dimensional stability in chemical solutions, heat, and moisture. Applications for Upilex polyimide include flexible printed circuits, electric motor and generator insulation, high temperature wire and cable wrapping, composite molding and specialty pressure sensitive tapes [3]. Peek - polyetheretherketone is a high performance thermoplastic film with good electrical properties over a wide temperature range. This high temperature film has good resistance to radiation and finds applications in reinforced composites, electronics, and aerospace components [4]. Apical polyimide film is characterized by a wide range of operating temperature, improved long-term heat aging performance, and excellent dimensional stability. Its aerospace applications derive from its high dielectric strength and flexibility, and retention of key properties over a wide range of temperatures [5]. Teflon AF is an amorphous fluoropolymer with outstanding mechanical and electrical properties over a wide range of temperature. The material has low dielectric constant and dissipation factor and may be used in optoelectronic devices, special circuit boards, and hybrid systems [6]. Kapton is a polyimide film which possesses excellent physical, electrical, and mechanical properties over a wide temperature range. Typical applications for Kapton polyimide film include wire and cable tapes, formed coil and magnet wire insulation, and transformer and capacitor insulation [7].

The samples were characterized for their $60 \mathrm{~Hz} \mathrm{AC}$ and DC breakdown strength in air and in silicone oil as a function of temperature up to $250{ }^{\circ} \mathrm{C}$. Dielectric characterization of the films in terms of dissipation factor and dielectric constant was also obtained at high temperatures with an electrical stress of $60 \mathrm{~Hz}, 200 \mathrm{~V} / \mathrm{mil}$ present. Changes in the physical properties of the films were also obtained after thermal aging for 15 hours at temperatures of 200 and $250^{\circ} \mathrm{C}$, each. In this paper, the experimental procedures and the results obtained are reported and discussed.

\section{EXPERIMENTAL PROCEDURE}

The dielectric materials tested included Upilex and Peek (ICI Americas, Inc.), Apical (Allied-Apical Co.), and Teflon AF and Kapton (Du Pont Co.). All samples had a thickness of 1.0 mil except the Teflon film, which is in its developmental stage and had a thickness averaging about 5.0 mils. Some properties of the 
materials tested are given in Table I [3-7]. Dielectric characterization of the films in terms of their dielectric constant and dissipation factor was performed at 20,100, and $200^{\circ} \mathrm{C}$ with an applied electrical stress of $60 \mathrm{~Hz}, 200 \mathrm{~V} / \mathrm{mil}$ using Tettex Instruments, Type 2821 Capacitance System and Type 2914 Dielectric Test Cell. An electrical bias of $700 \mathrm{~V}$ was applied to the Teflon film.

A Hipotronics AC Dielectric Test Set, Model 7100-20A, and a Universal Voltronics DC power supply, Model BAM-32-1.5, were employed in the breakdown voltage measurements. The breakdown strengths were obtained for dry (in air) as well as for samples impregnated with Dow Corning Silicone fluid $210 \mathrm{H}$. The measurements were performed at temperatures of 20,125 , and $250^{\circ} \mathrm{C}$ where a temperature controller was utilized to maintain proper test temperatures within +1 $2{ }^{\circ} \mathrm{C}$. During testing, the specimen was held between two cylindrical brass electrodes of 0.25 inch diameter (ASTM D-149) and the voltage was raised at a rate of $500 \mathrm{~V} / \mathrm{s}$ until breakdown occurred. The values reported are the average of at least seven data points.

Changes in the physical properties of the films were obtained after thermal aging at 200 and $250^{\circ} \mathrm{C}$ for 15 hours, each. The properties included linear dimensional change, variation in thickness, weight loss, and physical appearance such as brittleness and discoloration. A Hotpack Digimatec benchtop oven was used for the aging and a Scientech SR 5200 balance was used to weight the samples.

\section{RESULTS AND DISCUSSION}

The dielectric properties, namely the dielectric constant $(\epsilon)$ and the dissipation factor (D.F.), of the films at three different temperatures are shown in Table II. These measurements were carried out at $200 \mathrm{~V} / \mathrm{mil}, 60 \mathrm{~Hz}$ electrical stress (except the Teflon film which had a $700 \mathrm{~V}$ stress applied). It can be seen that except for the Peek film, all polymers exhibited no significant change in their dielectric constant property with increase in temperature. The dissipation factor of all films, however, exhibited gradual increase with temperature. Such an effect is more profound on the Peek film even though these measurements were performed at a temperature of $150^{\circ} \mathrm{C}$. This was done because the multi-factor (electrical and thermal) stress on the film seemed to induce some wrinkling at higher temperatures. The increase in the dielectric loss of the films with increasing temperature can be contributed to softening of the polymers and to some thermally-induced molecular agitation phenomenon. The presence of electrical stress may have also contributed to such an effect.

A comparison of the AC and DC breakdown voltages for dry samples (in air) at three different temperatures is given in Table III. Once again, measurements performed on the Peek film were limited to about $185^{\circ} \mathrm{C}$ due to wrinkling of the film at high temperatures. The Teflon film was excluded from these tests due to the limited availability of samples. It can be seen that for both cases, AC and DC, the dielectric strengths of all films at $125^{\circ} \mathrm{C}$, in general, undergo little decrease 
from their room temperature values. As the test temperature is increased further to $250^{\circ} \mathrm{C}$, a marked decrease occurs in this property. The temperature-dependence of the breakdown behavior of the films can be attributed to softening of the polymers, and to an increase in the dissipation factor which, in turn, leads to increase in losses through the generation of heat and its build-up. Although there is an apparent reduction in the dielectric strength with temperature, all samples seem to retain at least $50 \%$ of their room temperature dielectric strength even at temperatures as high as $250^{\circ} \mathrm{C}$.

The AC and DC dielectric strengths for samples impregnated in silicone oil are shown in Table IV for three different temperatures. Similar to their dry counterpart, the impregnated samples exhibit a decrease in their breakdown voltage with increase in temperature. Such a trend, which occurs for both AC and DC cases, does not seem, however, to be as severe as that of the dry samples. This happens because the impregnant, which has higher dielectric strength than air, penetrates the material and fills the microvoids and gas cavities as these are usually considered as primary sites for breakdown initiation.

The effect of thermal aging on properties of the films was investigated by exposing the samples for 15 hours at temperatures of 200 and $250^{\circ} \mathrm{C}$, each. After each aging cycle, the sample was characterized in terms of linear dimensional changes, swelling or thickness variation, weight loss, discoloration and other physical appearances. These tests revealed that: a) all samples did not exhibit any noticeable dimensional change or weight loss with thermal aging; b) the Peek film underwent some wrinkling and became brittle and cloudy in color at temperatures of about $200{ }^{\circ} \mathrm{C}$ and higher; c) the Teflon AF film developed very few wrinkles only when aged at $250^{\circ} \mathrm{C}$; and d) no variation in thickness was observed upon thermal aging of all films except the Peek specimen due to wrinkling.

\section{CONCLUSION}

The preliminary data obtained in this work indicate that most of the tested films remain relatively stable when exposed to temperatures as high as $250^{\circ} \mathrm{C}$. The Peek film however tends to display some wrinkling and exhibit discoloration when exposed to temperatures of about $200{ }^{\circ} \mathrm{C}$ and higher. All other films displayed good dielectric and physical properties even up to a temperature of $250^{\circ} \mathrm{C}$. Further research and experimental studies are required to better and fully characterize these and other materials for potential use as high temperature capacitor dielectrics and wiring insulation in space-based applications.

\section{ACKNOWLEDGMENTS}

This work was supported by the NASA Lewis Research Center, Contract No. NAS3-25266, Task Order No. 5423-01, "High Temperature Dielectrics". The authors thank K. E. Morris (ICI Americas), D. Chan (Allied-Signal), and D. Kratzer (Du Pont) for supplying the samples. 


\section{REFERENCES}

[1] R. W. Bercaw, "Toward an Electrical Power Utility for Space Exploration", Proceedings of the European Space Power Conference, Madrid, Spain, October 2-6, 1989.

[2] E. Sugimoto, "Applications of Polyimide Films to the Electrical and Electronic Industries in Japan", IEEE Electrical Insulation Magazine, Vol. 5, No. 1, 1989.

[3] ICI Americas Inc., Upilex Polyimide Films, Bulletin 901-1, 8/88.

[4] ICI Americas Inc., Stabar High Temperature Films, Bulletin 902-1, 1/90.

[5] Allied-Apical Co., Apical Polyimide Film, Technical Data.

[6] Du Pont Co., Teflon AF 2400 Amorphous Fluoropolymer, Product Information.

[7] Du Pont Co., Kapton Polyimide Film, Summary of Properties, Bulletin E-93189, 3/88.

Table I. Properties of dielectrics tested [3-7].

\begin{tabular}{|c|c|c|c|c|c|}
\hline Property & Upilex & Peek & Apical & $\begin{array}{l}\text { Teflon } \\
\text { AF }\end{array}$ & Kapton \\
\hline Grade & S & K 200 & $100 \mathrm{AV}$ & 2400 & $\mathrm{H}$ \\
\hline Thickness (mil) & 1.0 & 1.0 & 1.0 & 5.0 & 1.0 \\
\hline $\begin{array}{l}\text { Dielectric } \\
\text { Constant }\end{array}$ & $3.3-3.5$ & 3.3 & 3.4 & 1.9 & 3.4 \\
\hline $\begin{array}{l}\text { Dissipation } \\
\text { Factor }\left(\times 10^{-4}\right)\end{array}$ & $13-78$ & 18 & 14 & $1-3$ & 18 \\
\hline $\begin{array}{l}\text { Dielectric } \\
\text { Strength } \\
(\mathrm{kV} / \mathrm{mil})\end{array}$ & 6.8 & 3.2 & 7.8 & - & 7.7 \\
\hline $\begin{array}{l}\text { Long Term } \\
\text { Temp. }\left({ }^{\circ} \mathrm{C}\right)\end{array}$ & $\begin{array}{l}270 \text { to } \\
290\end{array}$ & 250 & $\begin{array}{c}-269 \text { to } \\
400\end{array}$ & 285 & $\begin{array}{c}-269 \text { to } \\
400\end{array}$ \\
\hline Shrinkage (\%) & $0.07-0.39$ & 0.5 & $0.05-1.00$ & - & $0.17-1.25$ \\
\hline Density $(g / c c)$ & 1.47 & 1.26 & 1.42 & 1.67 & 1.42 \\
\hline
\end{tabular}


Table II. Dielectric properties versus temperature.

\begin{tabular}{||c|c|c|c|c||}
\hline Sample & Property & $20^{\circ} \mathrm{C}$ & $100^{\circ} \mathrm{C}$ & $200^{\circ} \mathrm{C}$ \\
\hline Upilex & $\epsilon$ & 3.36 & 3.81 & 3.72 \\
& D.F. & 0.0012 & 0.0038 & 0.0043 \\
Peek & $\epsilon$ & 3.13 & 3.30 & $4.90^{*}$ \\
& D.F. & 0.0008 & 0.0023 & $0.0117^{*}$ \\
Apical & $\epsilon$ & 3.29 & 3.14 & 3.03 \\
& D.F. & 0.0031 & 0.0049 & 0.0110 \\
Teflon AF & $\epsilon$ & 1.84 & 1.94 & 1.95 \\
& D.F. & 0.0002 & 0.0006 & 0.0029 \\
Kapton & $\epsilon$ & 3.23 & 3.26 & 3.28 \\
& D.F. & 0.0100 & 0.0222 & 0.0310 \\
\hline
\end{tabular}

* readings were taken at $150^{\circ} \mathrm{C}$.

Table III. Dielectric strength (kV) versus temperature in air.

\begin{tabular}{||c|c|c|c|c|}
\hline Sample & Property & $20^{\circ} \mathrm{C}$ & $125^{\circ} \mathrm{C}$ & $250^{\circ} \mathrm{C}$ \\
\hline Upilex & AC & 7.10 & 6.12 & 3.70 \\
& DC & 14.37 & 14.10 & 8.40 \\
Peek & AC & 7.20 & 5.90 & $4.37^{*}$ \\
& DC & 13.33 & 12.80 & $7.93^{*}$ \\
& AC & 7.73 & 7.35 & 5.63 \\
Kapton & DC & 15.33 & 15.87 & 9.23 \\
& AC & 7.73 & 7.37 & 5.23 \\
& DC & 15.37 & 15.41 & 9.53 \\
\hline
\end{tabular}

* readings were taken at $185^{\circ} \mathrm{C}$.

Table IV. Dielectric strength (kV) versus temperature in oil.

\begin{tabular}{|c|c|c|c|c|}
\hline Sample & Property & $20^{\circ} \mathrm{C}$ & $125^{\circ} \mathrm{C}$ & $250^{\circ} \mathrm{C}$ \\
\hline Upilex & AC & 7.07 & 6.85 & 6.80 \\
& DC & 12.60 & 12.00 & 10.50 \\
Peek & AC & 7.10 & 7.05 & $6.80^{*}$ \\
& DC & 10.40 & 9.00 & $8.60^{*}$ \\
Apical & AC & 7.40 & 7.10 & 7.00 \\
& DC & 12.17 & 11.60 & 8.90 \\
Teflon AF & AC & 11.95 & 11.90 & 9.40 \\
& DC & 40.20 & 39.17 & 31.14 \\
Kapton & AC & 7.13 & 7.08 & 6.90 \\
& DC & 12.00 & 11.30 & 7.80 \\
\hline
\end{tabular}

* readings were taken at $185^{\circ} \mathrm{C}$. 

Public reporting burden for this collection of information is estimated to average 1 hour per response, including the time for reviewing instructions, searching existing cata sources, gathering and maintaining the data needed, and completing and reviewing the collection of information. Send comments regarding this burden estimate or any other aspect of this collection of information, including suggestions for reducing this burden, to Washington Headquarters Services, Directorate for intormation Operations and Reports, 1215 Jefferson Davis Highway, Suite 1204, Arlington, VA 22202-4302, and to the Office of Management and Budget, Paperwork Reduction Project (0704-0188), Washington, DC 20503.

1. AGENCY USE ONLY (Leave blank)

4. TITLE AND SUBTITLE
2. REPOAT DATE

October 1992
3. REPORT TYPE AND DATES COVERED

Technical Memorandum

High Temperature Dielectric Properties of Apical, Kapton, Peek, Teflon $\mathrm{AF}$, and Upilex Polymers

5. FUNDING NUMBERS

WU $-506-41-41$

6. AUTHOR(S)

A.N. Hammoud, E.D. Baumann, E. Overton, I.T. Myers, J.L. Suthar, W. Khachen, and J.R. Laghari

7. PERFORMING ORGANIZATION NAME(S) AND ADDRESS(ES)

8. PERFORMING ORGANIZATION REPORT NUMBER

National Aeronautics and Space Administration

Lewis Research Center

Cleveland, Ohio 44135-3191

E-7161

9. SPONSORING/MONITORING AGENCY NAMES(S) AND ADDRESS(ES)

10. SPONSORING/MONITORING AGENCY REPORT NUMBER

National Aeronautics and Space Administration

Washington, D.C. 20546-0001

NASA TM-105753

\section{SUPPLEMENTARY NOTES}

Prepared for the 1992 Conference on Electrical Insulation and Diclectric Phenomena, sponsored by the Institute of Electrical and Electronics Engineers, Victoria, British Columbia, Canada, Octuber 18-21, 1992. A.N. Hammoud, Sverdrup Technology, Inc., Lewis Research Center Group, Brook Park, Ohio 44135. E.D. Baumann, E. Overton, and I.T. Myers, NASA Lewis Research Center, Cleveland, Ohio 44135. J.L. Suthar, W. Khachen, and J.R. Laghari, State University of New York at Buffalo, Buffalo, New York 14260. Responsible person, E.D. Baumann, (216) 433-6113.

12a. DISTRIBUTION/AVAILABILITY STATEMENT

12b. DISTRIBUTION CODE

Unclassified - Unlimited

Subject Category 33

\section{ABSTRACT (Maximum 200 words)}

Reliable lightweight systems capable of providing electrical power at the megawatt level are a requirement for future manned space exploration missions. This can be achieved by the development of high temperature insulating materials which are not only capable of surviving the hostile space environment but can contribute to reducing the mass and weight of the heat rejection system. In this work, Apical, Upilex, Kapton, Teflon AF, and Peek polymers are characterized for $\mathrm{AC}$ and $\mathrm{DC}$ dielectric breakdown in air and in silicone oil at temperatures up to $250^{\circ} \mathrm{C}$. The materials are also tested in terms of their dielectric constant and dissipation factor at high temperatures with an electrical stress of $60 \mathrm{~Hz}, 200 \mathrm{~V} / \mathrm{mil}$ present. The effects of thermal aging on the properties of the films are determined after 15 hours of exposure to 200 and $250{ }^{\circ} \mathrm{C}$, each. The results obtained are discussed and conclusions are made concerning the suitability of these dielectrics for use in capacitors and cable insulations in high temperature environments.

\begin{tabular}{|c|c|}
\hline $\begin{array}{c}\text { 14. SUBJECT TERMS } \\
\text { Dielectrics; High temperature; Power components }\end{array}$ \\
\hline $\begin{array}{c}\text { 17. SECURTY CLASSIFICATION } \\
\text { OF REPORT } \\
\text { Unclassified }\end{array}$ & $\begin{array}{c}\text { 18. SECURITY CLASSIFICATION } \\
\text { OF THIS PAGE } \\
\text { Unclassified }\end{array}$ \\
\hline
\end{tabular}

\begin{tabular}{|c|c|}
\hline & $\begin{array}{l}\text { 15. NUMBER OF PAGES } \\
8\end{array}$ \\
\hline & $\begin{array}{r}\text { 16. PRICE CODE } \\
A 02\end{array}$ \\
\hline $\begin{array}{l}\text { 19. SECURITY CLASSIFICATION } \\
\text { OF ABSTRACT } \\
\text { Unclassified }\end{array}$ & 20. LIMITATION OF ABSTRACT \\
\hline
\end{tabular}

